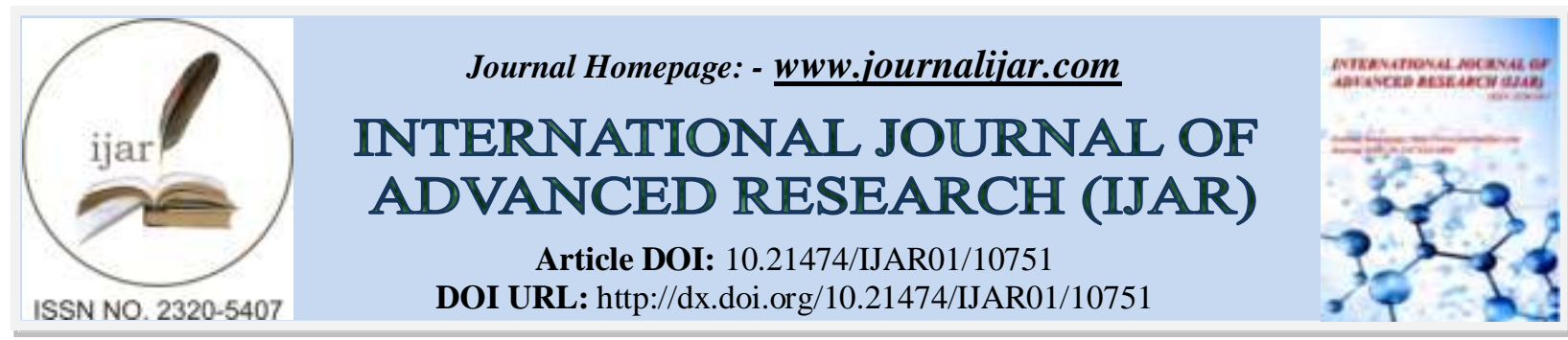

RESEARCH ARTICLE

\title{
MULTIPLE STRIP CROWNS IN PEDIATRIC DENTISTRY - A NOVEL APPROACH FOR ESTHETIC
} REHABILITATION

\author{
Dr. Pooja Goel ${ }^{1}$, Dr. Ambreena Khurshid ${ }^{1}$, Dr. Sanjay Chachra $^{2}$, Dr. Abhishek Dhindsa ${ }^{3}$, Dr. Manu Sharma ${ }^{1}$ \\ and Dr. Achla Sethi ${ }^{4}$ \\ 1. MDS Student, Swami Devi Dyal Hospital and Dental College, Barwala, Panchkula, Haryana, India. \\ 2. Professor and HOD, Swami Devi Dyal Hospital and Dental College, Barwala, Panchkula, Haryana, India. \\ 3. Professor, Swami Devi Dyal Hospital and Dental College, Barwala, Panchkula, Haryana, India. \\ 4. Senior Lecturer, Bhojia Dentl College and Hospital, Himachal Pradesh, India.
}

\section{Manuscript Info}

Manuscript History

Received: 05 February 2020

Final Accepted: 07 March 2020

Published: April 2020

Key words:-

Strip Crown, Esthetics, Retention, Pediatric Dentistry, Dental caries

\begin{abstract}
Even with all the preventive measures used in pediatric dentistry, early childhood caries is a problem outfaced day to day in pediatric dentistry which predominantly affects the labial surfaces of the anterior teeth in children younger than 71 months. The current study reports a case of aesthetic-functional restoration performed with the help of prefabricated strip crowns and composite in a 4-year-old female patient affected by multiple carious lesions in primary maxillary anterior teeth. Composite resin restorations were performed on all upper anterior teeth to restore aesthetics and function, offering a better quality of oral health for the child. The procedure of composite resin restorations with the help of strip crowns resulted in a shorter clinical time, a better aesthetic result, function and the restoration of the patient's good smile.
\end{abstract}

Copy Right, IJAR, 2020,. All rights reserved.

\section{Introduction:-}

The most common botheration in childhood leading to structural damage of primary maxillary anterior teeth include early childhood caries and dental trauma. Structural loss of these teeth not only affects esthetics, but also leads to compromised mastication, poor phonetics along with a difficulty in social and physiological adjustment.Hence, esthetic and functional rehabilitation of these decayed and traumatized primary teeth should always be the major treatment objective.

The primary maxillary incisors teeth are small and require restorations that are retentive, esthetic and resistant to fracture and wear, therefore, difficult to treat.Such teeth can be restored using either intracoronal or full-coronal restorations. Intra-coronal restorations are indicated for single-surface caries and include tooth-colored materials like composites, glass ionomer cement, etc, while for teeth with multisurface caries involvement and traumatized/ discolored teeth, full-coronal restorations are preferred. Other full-coronal restorations include prefabricated zirconia, preveneered stainless steel, and polycarbonate crowns. These crowns exhibit better esthetics and retention, but their higher cost and difficult adaptation are some of the limitations ${ }^{[2]}$ Hence, an alternative would be to fabricate chair-side, customized full-coronal restoration, which should also be esthetic, durable, and cheap.

The most common alternative method for restoring such teeth involves the use of 'Strip crowns'(celluloid forms) with composites. These restorations exhibit good esthetics and high success rate, but difficult moisture control, 
decreased surface area, and technique sensitivity frequently compromise the retention and success of these restorations.This case report depicts the restorations with the aid of strip crown as a full-coronal restorations in primary maxillary anterior teeth.

\section{Case Report:}

A 4 year old girl reported to the outpatient Department of Pedodontics and Peventive Dentistry with the chief complaint of dislodged filling in the upper front teeth region since 15 days. There was no associated pain and sensitivity present but her parents were quite concerned about the esthetic appearance and retention of the restoration. Medical and family history was non contributory. On intraoral examination, distinct cavity preparations were seen wrt 52,61,62. The remaining restorative material was carefully removed from the cavity. After excavation of the previous restoration, all the lesions were well appreciated till the dentine thicknessand no pulp exposure were seen. Further, it was also observed that all the teeth were asymptomatic with no signs of tender on percussion, mobility and sinus tract.Consequently, treatment planning incorporated the restoration of teeth with strip crowns for the retention and esthetic purpose.

The parents were informed about the procedure and an informed written consent was taken.

\section{Clinical procedure:}

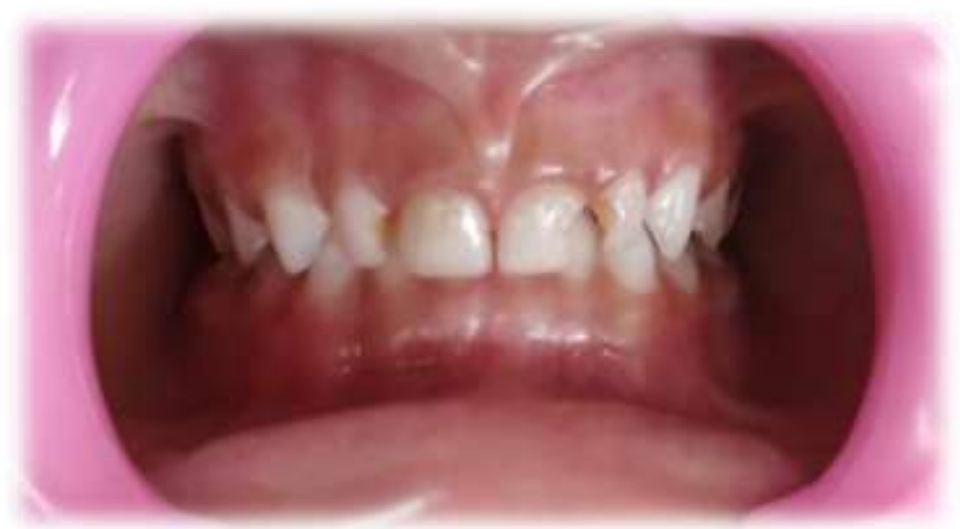

Figure.1:- Preoperative intraoral viewshowing the dislodged restoration wrt 52, 61, 62.

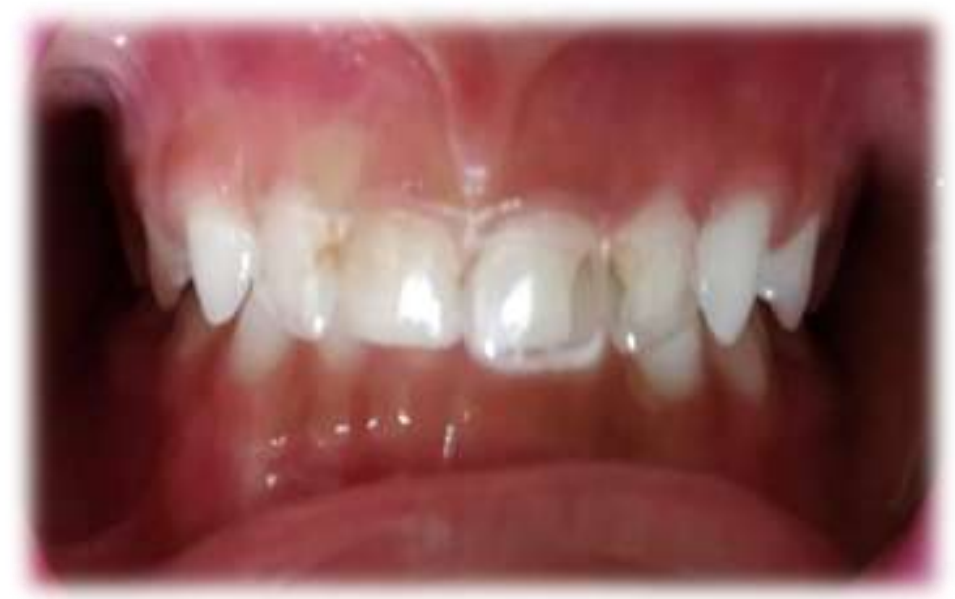

Figure.2:- Trial fit of Strip Crowns according to the mesiodistal width. 

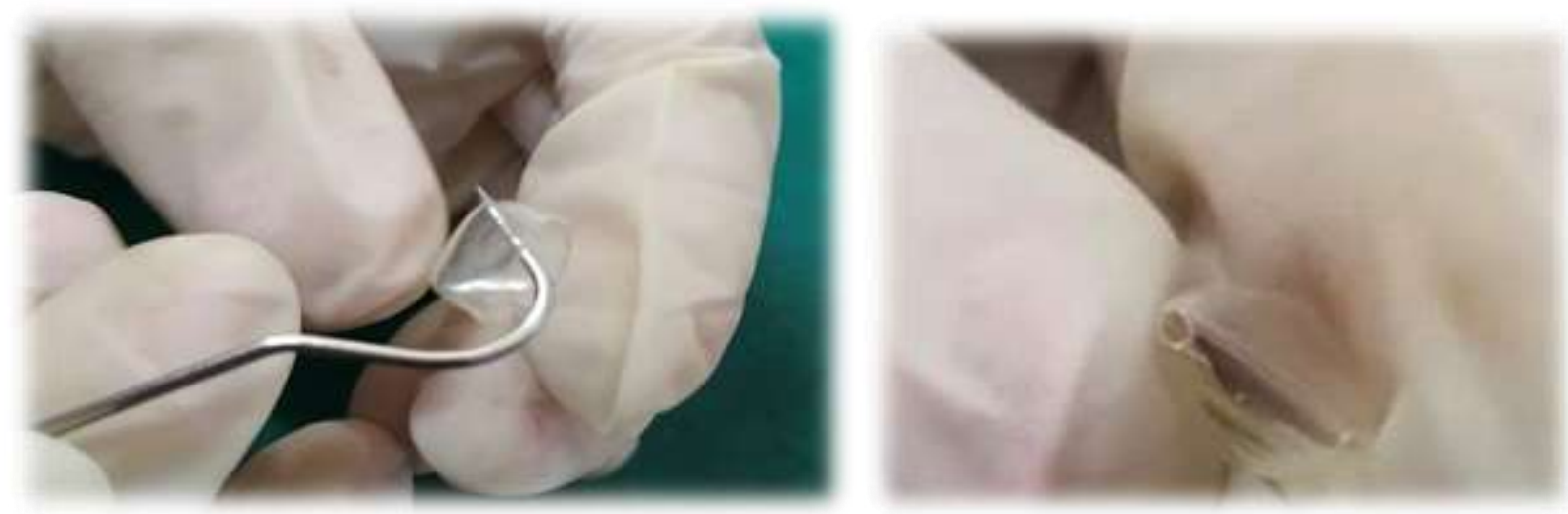

Figure.3:- Vents are placed with a sharp explorer on mesial and distal corners of the incisal edge in order to allow for overflow of excess restorative material.

The prepared tooth surface was dried, and the self-etch adhesive system was applied and cured. The strip crown was filled with composite resin using light pressure to avoid air bubbles and placed on the prepared tooth, avoiding too much pressure to prevent splitting and then cured.
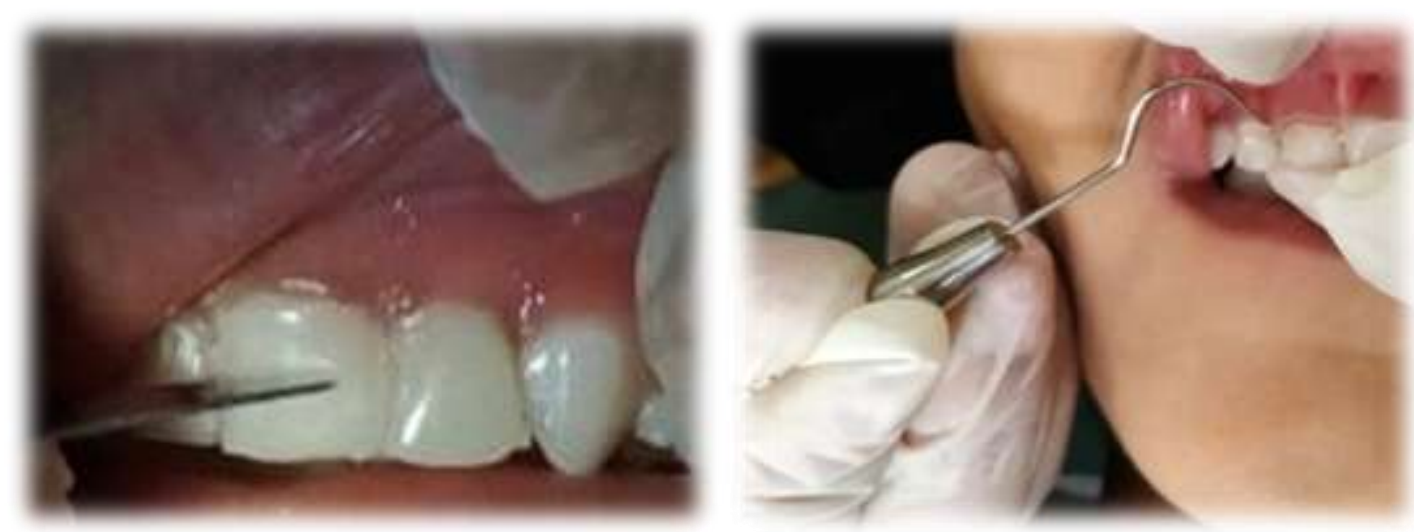

Figure.4:- The strip crown shell was then peeled off with the help of an explorer.

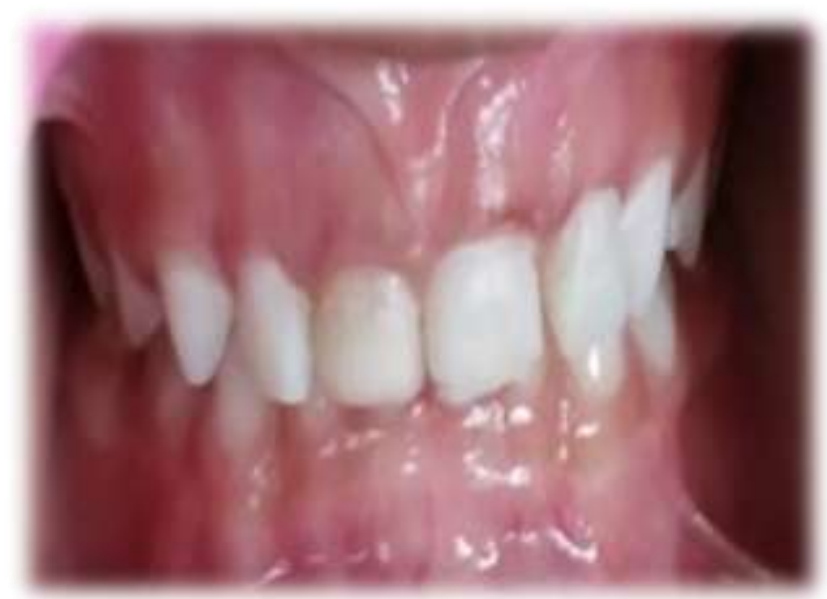

Figure.5:- Completed strip crown restoration (Finishing and occlusal adjustments were performed, if required, using polishing discs.). 


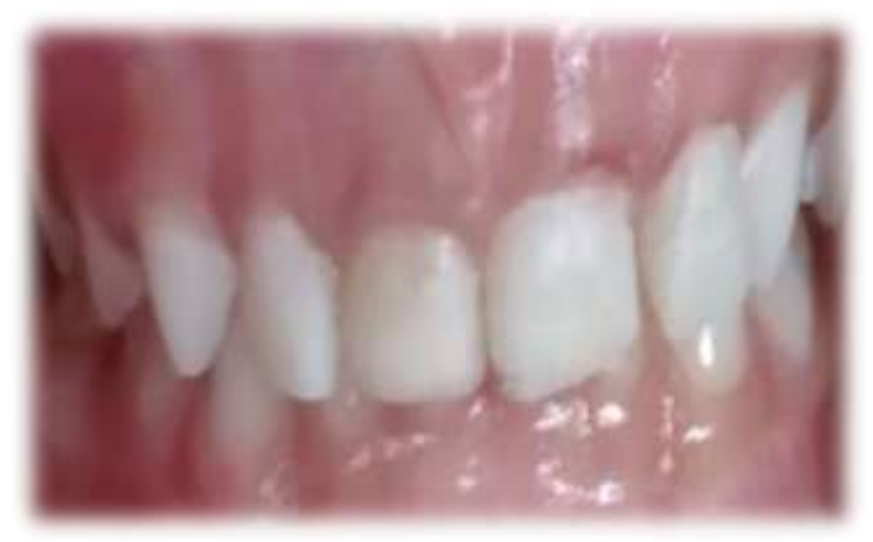

Figure.6:- Follow up done after 3 months.

\section{Discussion:-}

Deciduous teeth play a foremost role in phonetics, eating, aesthetics and maintaining space for permanent teeth. Thus, pediatric dentistry should invest efforts to keep these dental elements healthy until the time of their natural exfoliation and emergence of permanent successors. When caries lesion is installed, problems such as pain, swelling, irritation, poor nutrition, functional insatiability, among others, can cause excruciation and discomfort in the child, affecting their behavior, appearance, chewing capacity and phonation. For correct planning and treatment, dentist must consider the aesthetic and functional aspects. There are several treatments and materials which intent to restore aesthetics and function, as well as to prevent the recurrence of caries lesion under restorations. However, the bonded resin composite strip crownis perhaps the most esthetic of all the restorations available for the treatment of severely decayed primary incisors. Besides that operator preferences, esthetic demands by parents, the child's behavior, moisture and hemorrhage control;poor compliance with intra operative and post-operative instructionsare all variables which affect the decision and ultimate outcome of whatever restorative treatment is chosen. The presence of aprismatic enamel on primary teeth surface is another challenge which compromises adhesive bonding restorative leading to frequent failures.

In the presented case, the multisurface involvement of primary maxillary teeth, the caries were not extending into the pulp and a significant amount of tooth structure was present for the retention of an adhesive material like composite resin. Hence the bonded composite resin strip crowns restoration were decided and it exhibit excellent aesthetics and patient satisfaction but the difficulty in moisture controland technique sensitivity often compromise the retention and the longevity of the restoration.

The bonded resin composite strip crown is perhaps the most esthetic of all the restorations available to the linician for the treatment of severely decayed primary incisors. However, strip crowns are also the most techniqueensitive and may be difficult to place. Composite strip crowns are composite filled celluloid crowns forms. They ave ecome a popular method of restoring primary anterior teeth because they provide superior aesthetics as compared o other forms of anterior tooth coverage. Composite strip crowns rely oSome authors have introduced modifications to the technique of strip crown placement.An author illustrated the 'Sandwich technique' in which a layer of resin-modified glass ionomer cement is placed to enclose allthe exposed dentin before seating of the crown filled with composite resin. ${ }^{[3]}$ This dentin replacement with a layer of glass ionomer cement was used to prevent debonding of composite materials in areas where enamel was lacking, including the gingival margins. Kenny et al. (1986) introduced the composite resin short post, or "mushroom undercut" in the dentin, to aid in the retention of the crown. Strip crown restoration can prove as a simple, economic, effective and appropriatetechnique that will satisfy all the requirements of dental personnel for esthetic management of anterior teeth. ${ }^{[4]}$

\section{Conclusion:-}

Composite restoration made with the adjunct of strip crowns provides a shorter clinical time, aesthetic result, reestablishment of the patient's smile.

\section{Conflicts of interest:}

Nil. 


\section{References:-}

1. Gaurav Kumar Mittal, Aviral Verma, Hansika Pahuja, Shashank Agarwal, Himani Tomar. Esthetic crowns in pediatric dentistry: a review. Int J of Contemp Med Res 2016;3(5):1280-1282.

2. Walia T, Salami A, Bashiri R, Hamoodi OM, Rashid F. A randomised controlled trial of three aesthetic fullcoronal restorations in primary maxillary teeth. Eur J of Paedia Dent2014 ;15(2):113-118

3. Margolis FS. The sandwich technique and strip crowns: an esthetic restoration for primary incisors. Compend Contin Educ Dent2002, 23(12), 1165-1169.

4. Kenny DJ, Johnston DH, Bamba S. The composite resin short-post: a review of 625 teeth. Ont Dent1986;63(5):12-18.

5. Muhamad A, Azzaldeen A, Mai A. Strip Crowns Technique for Restoration of Primary Anterior Teeth: Case Report.IOSR-JDMS.2015;14(12):48-53.

6. Ephraim R, Rajamani T, Ambili Ayilliath Arifa M.K. Aesthetic Rehabilitation of Maxillary Primary Anterior Teeth with Early Childhood Caries - Report of Three Different Cases. Int J Dent Sci and Res2017,5(6):159162.

7. Doneria D, Thakur S, Singhal P, Chauhan D. Complete mouth rehabilitation of children with early childhood caries: A case report of three cases. Int J Pedod Rehabil 2017;2:37-40. 